\title{
PENERAPAN PENGUJIAN ALPHA DAN BETA PADA APLIKASI PENERIMAAN SISWA BARU
}

\author{
Siti Masripah ${ }^{1}$, Linda Ramayanti ${ }^{2}$ \\ ${ }^{1}$ Universitas Bina Sarana Informatika \\ e-mail: siti.stm@bsi.ac.id \\ 2Universitas Bina Sarana Informatika \\ e-mail: lindaramayani97@gmail.com
}

\begin{abstract}
Abstrak
Aplikasi yang sudah dirancang dengan menggunakan pengembangan sistem yaitu SDLC, dapat dinyatakan valid dan sesuai dengan apa yang diharapkan jika sudah dilakukan pengujian. Penelitian terdahulu menyatakan sistem informasi penerimaan siswa baru yang sudah diuji menggunakan black box testing dapat dinyatakan valid karena sudah melalui tahapan pengujian. Hanya saja pengujian yang dilakukan hanya untuk menampilkan apakah fungsi masukan dan keluaran sesuai dengan apa yang diharapkan. Suatu aplikasi dapat dilakukan pengujian menggunakan kolaborasi antara pengujian alpha dan beta yang menggunakan metode black box, untuk mendapatkan tingkat yang lebih valid dan dapat mengetahui presentase atau rata-rata nilai sebuah sistem dinyatakan valid. Pengujian alpha dilakukan untuk melihat apakah semua sistem dapat berjalan dengan baik dan dilakukan oleh pembuat sistem atau yang terlibat dalam pembuatan sistem sedangkan pengujian beta digunakan untuk melakukan evaluasi terhadap sistem yang telah dibuat, pihak yang akan melakukan penilaian sistem adalah pengguna atau orang-orang yang tidak terlibat dalam pembuatan sistem penerimaan siswa baru dengan cara menyebarkan kuesioner ke beberapa pengguna atau responden untuk melakukan penilaian terhadap aplikasi yang telah dibangun, sehingga dapat disimpulkan apakah aplikasi penyewaan ruangan ini telah sesuai dengan tujuan atau tidak, hasil dari uji Beta sebagai berikut : untuk soal no 1 dengan nilai $75 \%$, soal no 2 dengan nilai $85 \%$, soal no 3 dengan nilai $80 \%$, soal no 4 dengan nilai $75 \%$, soal no 5 dengan nilai $75 \%$, soal no 6 dengan nilai $75 \%$, soal no 7 dengan nilai $80 \%$, soal no 8 dengan nilai $75 \%$, soal no 9 dengan nilai $75 \%$, soal no 10 dengan nilai $90 \%$. Dengan rata-rata nilai $78,5 \%$.
\end{abstract}

Kata kunci : Alpha Testing, Beta Testing, sistem pendaftaran

\begin{abstract}
Applications that have been designed using the system development namely SDLC, can be declared valid and in accordance with what is expected if it has been tested. Previous research states that the new student admission information system that has been tested using black box testing can be declared valid because it has passed the testing stage. It's just that the test is done only to show whether the input and output functions match what is expected. An application can be tested using collaboration between alpha and beta testing using the black box method, to get a more valid level and can find out the percentage or average value of a system otherwise valid. Alpha testing is carried out to see whether all systems can run well and is carried out by the system maker or involved in making the system while beta testing is used to evaluate the system that has been made, the party that will carry out the system evaluation are users or people who are not involved in making a new student admission system by distributing questionnaires to several users or respondents to make an assessment of the application that has been built, so it can be concluded whether the application for renting the room is in accordance with the objectives or not, the results of the Beta test are as follows: 1 with a value of 75\%, question no. 2 with a value of $85 \%$, question no. 3 with a value of $80 \%$, question no. 4 with a value of $75 \%$, question no. 5 with a value of $75 \%$, question no. 6 with a value of $75 \%$, question no. 7 with value $80 \%$, question no 8 with a value of $75 \%$, question no. 9 with a value of $75 \%$, question no. 10 with a value of $90 \%$. With an average value of $78.5 \%$.
\end{abstract}

Keywords: Alpha Testing, BetaTesting, Registration System 1. Pendahuluan

Diterima Februari 10, 2020; Revisi Februari 16 , 2020; Disetujui Maret 15, 2020 
Pada penelitian terdahulu sebuah sistem penerimaan siswa baru yang telah selesai dirancang, dilakukan pengujian menggunakan black box testing, untuk melihat apakah sistem berjalan dengan baik atau dinyatakan valid (Masripah \& Ramayanti, 2019).

Pengujian adalah kegiatan dimana suatu sistem atau komponen dieksekusi dibawah kondisi tertentu, hasilnya diamati atau dicatat untuk kemudian dievaluasi berdasarkan aspek sistem atau komponen (Galin, 2018).

Teknik pengujian atau testing yaitu black box testing, dimana akan terlihat hasil pengujiannya dengan bentuk tabel dengan field hasil pengujian dan kesimpulan yang dapat dilihat hasilnya(Cahyani, Indriyanto, \& Masripah, 2016). Pengujian perangkat lunak yang sering digunakan adalah black box testing (Safitri \& Pramudita, 2018).

Pada penelitian taufik yang menggunakan Teknik pengujian alpha, mengatakan bahwa pengujian alpha adalah pengujian yang bertujuan untuk memastikan bahwa aplikasi yang diuji dapat berjalan dengan lancer tanpa ganguan error atau bug (At Taufiq \& Hidayati, 2016)

Pengujian Beta merupakan pengujian yang bersifat langsung di lingkungan yang sebenarnya dengan penyebaran kuesioner yang akan dihitung untuk dapat diambil kesimpulan terhadap penilaian aplikasi yang dibangun (Suandi, Khasanah, \& Retnoningsih, 2017). Oleh karena itulah pada penelitian ini, penulis mengembangkan dengan melakukan kolaborasi antara pengujian alpha menggunakan Teknik black box testing dan beta testing.

\section{Metode Penelitian}

Dalam penelitian ini metode yang digunakan adalah dengan System Development Life Cycle (SDLC) menggunakan metode waterfall.

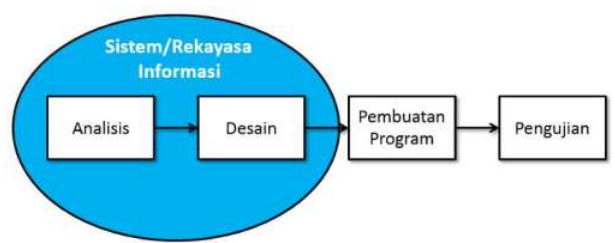

Gambar 1. Ilustrasi model Waterfall Sumber : Sukamto \& Shalahuddin (2014)

Adapun alur yang dilakukan yaitu 1) Analisa, melakukan Analisa kebutuhan perangkat lunak yang dibutuhkan sistem, dimana kebutuhan sistem ini dapat digambarkan dengan use case diagram. 2) Desain, pada tahapan ini dilakukan desain perangkat lunak berupa pembuatan rancang struktur data, arsitektur perangkat lunak, antarmuka dan pengkodean yang dilakukan. 3) Pengujian, pengujian yang dilakukan menggunakan pengujian Alpha dengan metode Black box dan pengujian Beta dengan penyebaran kuesioner. 4)Pendukung, software dan hardware apa saja yang dibutuhkan dalam sistem penyewaan ruangan berbasis web.

Penekanan pada penelitian ini adalah tentang pengujian, pengujian yang dilakukan menggunakan alpha testing dengan metode black box dan beta testing dengan penyebaran kuesioner, dimana pengguna akan menilai sejauh mana aplikasi berjalan sesuai tujuan.

Berikut adalah gambar diagram pengujian beta dalam siklus hidup pengembangan perangkat lunak :

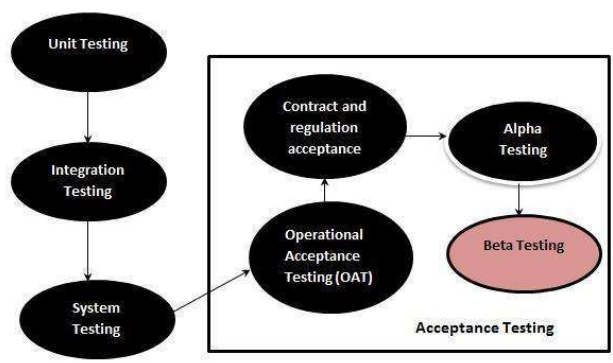

Gambar 2 . Beta Testing dalam SDLC Sumber : ("Tutorialspoint," n.d.)

Untuk melakukan perhitungan kuesioner menggunakan rumus :

$$
Y=\frac{2(N . R)}{\text { Skor Ideal }} \times 100 \%
$$

Keterangan :

$Y=$ Nilai persentase yang dicari

$\mathrm{X}=$ Jumlah nilai kategori jawaban dikalikan dengan frekuensi

$\mathrm{N}=$ Nilai dari setiap jawaban

$\mathrm{R}=$ Frekuensi

Skor ideal $=$ Nilai tertinggi dikalikan dengan jumlah sampel $(4 \times 5=20)$

Sumber : (Suandi et al., 2017)

\section{Hasil dan Pembahasan}


Pembahasan dalam penelitian ini memiliki konsep kerangka pemikiran yaitu : a)Problem : Apakah aplikasi yang digunakan sudah valid dan efektif ?, b) Approach : metode yang digunakan untuk perancangan sistem informasi penerimaan siswa baru berbasis web adalah System Development Life Cicle (SDLC) dan pengujian Alpha dan Beta, c) Development : Bahasa yang digunakan dalam merancang sistem penerimaan siswa baru adalah php, java dan sql. d) Implementation :Sistem informasi penerimaan siswa. e) Testing : pada tahap pengujian untuk sistem penyewaan ruangan ini menggunakan pengujian Alpha dan Beta testing. f) Result : Penerapan pengujian Alpha dan Beta pada Aplikasi Penerimaan Siswa Baru.

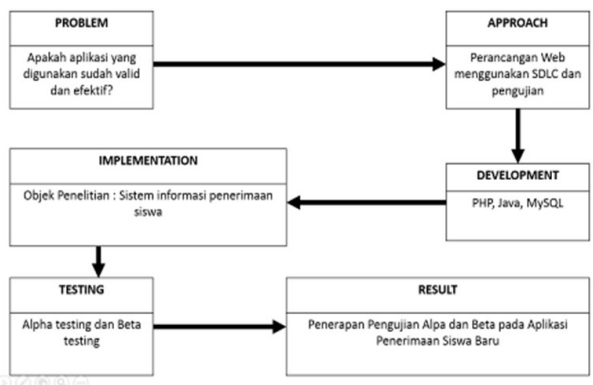

Gambar 3. Kerangka Pemikiran Sumber : Hasil penelitian (2020)

Pengujian merupakan tahap pengujian program atau aplikasi yang telah dibangun, dengan tujuan untuk menilai apakah aplikasi yang dibuat sesuai dengan tujuan yang diharapkan dan menilai apakah aplikasi bisa diterapkan dengan baik.

1. Hasil Pengujian Alpha

Hasil pengujian alpha dengan Teknik black box, pada beberapa user interface ( halaman utama aplikasi dan halaman Log In)

Berikut adalah tampilah home untuk Aplikasi Penerimaan siswa baru, peneliti akan menguji apakah untuk masuk kedalam sistem dengan inputan log in akan menghasilkan output yang diinginkan yaitu ke halaman admin.

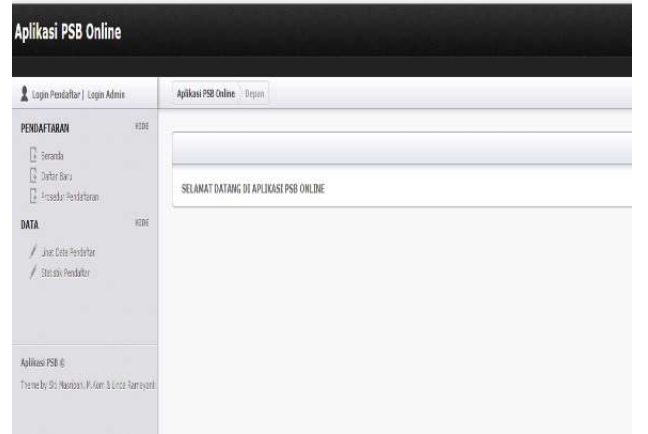

Gambar 4. Halaman Utama

Pada gambar 4 adalah halaman utama user, untuk mengakses aplikasi tersebut harus dilakukan log in.

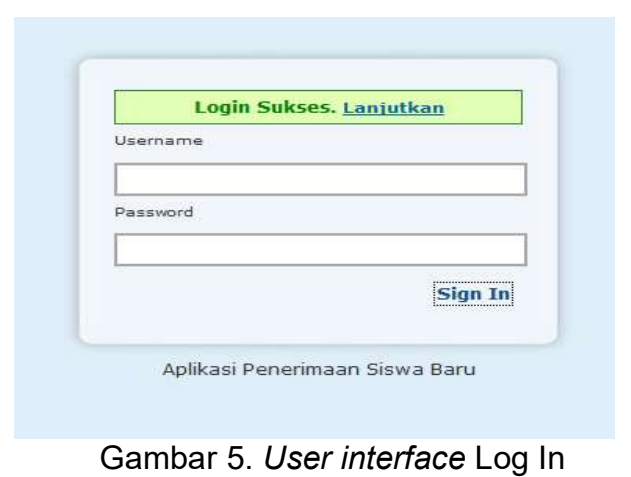

pada gambar 5 , Skenario Pengujian yang pertama adalah dengan Mengosongkan semua data log in lalu mengklik Sign In dengan hasil yang diharapkan adalah sistem akan menolak akses log in dan menampilkan pesan "This Field is required". Skenario pengujian yang kedua Menginput username dan password yang salah kemudian klik Sign In dengan hasil yang diharapkan adalah sistem akan menolak akses log in dan menampilkan pesan "Login Gagal. Periksa Kembali”. Skenario pengujian yang ketiga Menginput data username dan password dengan benar kemudian klik Sign In, dengan hasil yang diharapkan adalah Sistem akan menerima akses login dan menampilkan pesan "Login sukses Lanjutkan" dan akan masuk ke halaman utama.

Hasil pengujian Alpha menggunakan metode black box dilakukan untuk memastikan apakah aplikasi dapat berjalan dengan baik, contoh pengujian dilakukan pada user interface Login.

Skenario pengujian yang ada, dapat dibuatkan tabel seperti pada tabel 1 . 
Tabel 1. Pengujian Alpha Log In

\begin{tabular}{|c|c|c|c|}
\hline $\begin{array}{l}\mathbf{N} \\
\mathbf{0}\end{array}$ & $\begin{array}{l}\text { Skenario } \\
\text { Pengujian }\end{array}$ & $\begin{array}{l}\text { Hasil yang } \\
\text { dharapkan }\end{array}$ & $\begin{array}{l}\text { Hasil } \\
\text { Pengujian }\end{array}$ \\
\hline 1. & $\begin{array}{l}\text { Mengosong } \\
\text { kan semua } \\
\text { data login } \\
\text { lalu } \\
\text { langsung } \\
\text { mengklik } \\
\text { Sign In } \\
\text { Username : } \\
\text { (kosong) } \\
\text { Password: } \\
\text { (kosong) }\end{array}$ & $\begin{array}{l}\text { Sistem akan menolak } \\
\text { akses login dan } \\
\text { menampilkan pesan } \\
\text { "This Field is required". }\end{array}$ & $\begin{array}{l}\text { Sesuai } \\
\text { harapan }\end{array}$ \\
\hline 2. & $\begin{array}{l}\text { Menginput } \\
\text { username } \\
\text { dan } \\
\text { password } \\
\text { yang salah, } \\
\text { kemudian } \\
\text { klik Sign In } \\
\text { Username: } \\
\text { admin } \\
\text { Password: } \\
123456\end{array}$ & $\begin{array}{l}\text { Sistem akan menolak } \\
\text { akses login dan } \\
\text { menampilkan pesan " } \\
\text { Login Gagal. Periksa } \\
\text { Kembali" }\end{array}$ & $\begin{array}{l}\text { Sesuai } \\
\text { harapan }\end{array}$ \\
\hline 3. & $\begin{array}{l}\text { Menginput } \\
\text { data } \\
\text { username } \\
\text { dan } \\
\text { password } \\
\text { dengan } \\
\text { benar } \\
\text { kemudian } \\
\text { klik Sign In } \\
\text { Username: } \\
\text { admin } \\
\text { Password: } \\
\star \star \star \star *\end{array}$ & $\begin{array}{l}\text { Sistem akan } \\
\text { menerima akses log in } \\
\text { dan menampilkan } \\
\text { menu utama program } \\
\text { ppdb }\end{array}$ & $\begin{array}{l}\text { Sesuai } \\
\text { harapan }\end{array}$ \\
\hline
\end{tabular}

2. Hasil Pengujian Beta

Untuk pengujian beta, dilakukan kepada pengguna, dan tanpa kehadiran pihak pembuat aplikasi dibutuhkan kuesioner yang harus diisi guna mengetahui apakah atau seberapa baikkah website yang dibuat. Kuesioner terdiri dari sepuluh pertanyaan yang ditujukan kepada lima responden. Responden akan menjawab sepuluh pertanyaan yang diberikan terkait dengan program yang telah dibuat.

Kuesioner menggunakan skala likert dari skala 1 sampai 4 . Berikut skor penilaian yang menggunakan skala likert pada tabel 2 . Tabel 2. Tabel Skala Penilaian

\begin{tabular}{ll}
\hline Tingkat kepuasan & Skala \\
\hline Sangat Setuju & 4 \\
\hline Setuju & 3 \\
\hline Tidak Setuju & 2 \\
\hline Sangat Tidak Setuju & 1 \\
\hline Sumber : (Suandi et al., 2017)
\end{tabular}

Sumber : (Suandi et al., 2017)

\begin{tabular}{llllll}
\hline $\begin{array}{l}\text { Pert } \\
\text { any } \\
\text { aan }\end{array}$ & $\mathrm{N}$ & Keterangan & $\begin{array}{l}\text { Skal } \\
\mathrm{a} \\
(\mathrm{N})\end{array}$ & $\begin{array}{l}\text { Respond } \\
\text { en }(\mathrm{R})\end{array}$ & $\begin{array}{l}\mathrm{N} . \\
\mathrm{R}\end{array}$ \\
\hline 2 & 1 & Tidak Baik & 1 & 0 & 0 \\
\hline & 2 & Kurang Baik & 2 & 0 & 0 \\
\hline & 3 & Baik & 3 & 3 & 9 \\
\hline & 4 & Sangat Baik & 4 & 2 & 8 \\
\hline & Jumlah & & 5 & 17 \\
\hline
\end{tabular}

Sumber: Hasil penelitian (2020)

Hasil pengujian beta dengan soal Kemudahan dalam pengoperasian website Penerimaan Siswa Baru Online menunjukan bahwa 3 dari 5 responden memberi nilai Baik, 2 dari 5 responden memberikan nilai sangat baik, sehingga diperoleh nilai $\mathrm{Y}=$ $17 / 20 \times 100=85 \%$.

3. Kecepatan akses website Penerimaan Siswa Baru :

Tabel 5. Pengujian kuesioner soal 3

\begin{tabular}{llllll}
\hline $\begin{array}{l}\text { Pert } \\
\begin{array}{l}\text { any } \\
\text { aan }\end{array}\end{array}$ & No & Keterangan & $\begin{array}{l}\text { Skal } \\
\text { a } \\
(\mathrm{N})\end{array}$ & $\begin{array}{l}\text { Respond } \\
\text { en }(\mathrm{R})\end{array}$ & $\begin{array}{l}\mathrm{N} . \\
\mathrm{R}\end{array}$ \\
\hline 3 & 1 & Tidak Baik & 1 & 0 & 0 \\
\hline & 2 & Kurang Baik & 2 & 0 & 0 \\
\hline 3 & Baik & 3 & 4 & 12 \\
\hline 4 & Sangat Baik & 4 & 1 & 4 \\
\hline & Jumlah & & 5 & 16 \\
\hline
\end{tabular}

Sumber : Hasil penelitian (2020)

Berikut hasil perhitungan kuesioner : 
Hasil pengujian beta dengan soal kecepatan akses website Penerimaan Siswa Baru menunjukan bahwa 4 dari 5 responden memberi nilai Baik, 1 dari 5 responden memberikan nilai sangat baik, sehingga diperoleh nilai $Y=16 / 20 \times 100=80 \%$.

4. Kelengkapan informasi yang disajikan pada website :

Tabel 6. Pengujian kuesioner soal 4

\begin{tabular}{llllll}
\hline $\begin{array}{l}\text { Pert } \\
\text { any } \\
\text { aan }\end{array}$ & No & Keterangan & $\begin{array}{l}\text { Skal } \\
\mathrm{a} \\
(\mathrm{N})\end{array}$ & $\begin{array}{l}\text { Respond } \\
\text { en }(\mathrm{R})\end{array}$ & $\begin{array}{l}\mathrm{N} . \\
\mathrm{R}\end{array}$ \\
\hline 4 & 1 & Tidak Baik & 1 & 0 & 0 \\
\hline & 2 & Kurang Baik & 2 & 0 & 0 \\
\hline & 3 & Baik & 3 & 5 & 15 \\
\hline & 4 & Sangat Baik & 4 & 0 & 0 \\
\hline & Jumlah & & 5 & 15 \\
\hline
\end{tabular}

Sumber : Hasil penelitian (2020)

Hasil pengujian beta dengan soal kelengkapan informasi yang disajikan pada website menunjukan bahwa 5 dari 5 responden memberi nilai Baik, sehingga diperoleh nilai $Y=15 / 20 \times 100=75 \%$.

5. Fitur yang memedai pada website Penerimaan Siswa Baru Online :

Tabel 7. Pengujian kuesioner soal 5

\begin{tabular}{llllll}
\hline $\begin{array}{l}\text { Pert } \\
\text { any } \\
\text { aan }\end{array}$ & No & Keterangan & $\begin{array}{l}\text { Skal } \\
\text { a } \\
(\mathrm{N})\end{array}$ & $\begin{array}{l}\text { Respond } \\
\text { en (R) }\end{array}$ & $\begin{array}{l}\mathrm{N} . \\
\mathrm{R}\end{array}$ \\
\hline 5 & 1 & Tidak Baik & 1 & 0 & 0 \\
\hline & 2 & Kurang Baik & 2 & 0 & 0 \\
\hline 3 & Baik & 3 & 5 & 15 \\
\hline & Sangat Baik & 4 & 0 & 0 \\
\hline & Jumlah & & 5 & 15 \\
\hline
\end{tabular}

Sumber : Hasil penelitian (2020)

Hasil pengujian beta dengan soal Fitur yang memadai pada website menunjukan bahwa 5 dari 5 responden memberi nilai Baik, sehingga diperoleh nilai $Y=15 / 20 \times 100=$ $75 \%$.

6. Ketersediaan navigasi pada website Penerimaan Siswa Baru Online :

Tabel 8. Pengujian kuesioner soal 6

\begin{tabular}{llllll}
\hline $\begin{array}{l}\text { Pert } \\
\text { any } \\
\text { aan }\end{array}$ & No & Keterangan & $\begin{array}{l}\text { Skal } \\
\text { a } \\
(\mathrm{N})\end{array}$ & $\begin{array}{l}\text { Respond } \\
\text { en }(\mathrm{R})\end{array}$ & $\begin{array}{l}\mathrm{N} . \\
\mathrm{R}\end{array}$ \\
\hline 6 & 1 & Tidak Baik & 1 & 0 & 0 \\
\hline & 2 & Kurang Baik & 2 & 0 & 0 \\
\hline 3 & Baik & 3 & 5 & 15 \\
\hline & Sangat Baik & 4 & 0 & 0 \\
\hline & & Jumlah & & 5 & 15 \\
\hline
\end{tabular}

Sumber : Hasil penelitian (2020)
Hasil pengujian beta dengan soal Ketersediaan navigasi pada website menunjukan bahwa 5 dari 5 responden memberi nilai Baik, sehingga diperoleh nilai $Y=15 / 20 \times 100=75 \%$.

7. Ketepatan fungsi tombol dengan tujuan menu yang diinginkan :

Tabel 9. Pengujian kuesioner soal 7

\begin{tabular}{llllll}
\hline $\begin{array}{l}\text { Pert } \\
\text { any } \\
\text { aan }\end{array}$ & No & Keterangan & $\begin{array}{l}\text { Skal } \\
\text { a } \\
(\mathrm{N})\end{array}$ & $\begin{array}{l}\text { Respond } \\
\text { en }(\mathrm{R})\end{array}$ & $\begin{array}{l}\mathrm{N} . \\
\mathrm{R}\end{array}$ \\
\hline 7 & 1 & Tidak Baik & 1 & 0 & 0 \\
\hline & 2 & Kurang Baik & 2 & 0 & 0 \\
\hline & Baik & 3 & 4 & 12 \\
\hline & Sangat Baik & 4 & 1 & 4 \\
\hline & Jumlah & & 5 & 16 \\
\hline
\end{tabular}

Sumber : Hasil penelitian (2020)

Hasil pengujian beta dengan soal Ketersediaan navigasi pada website menunjukan bahwa 4 dari 5 responden memberi nilai Baik, 1 dari 5 responden memberikan nilai Sangat Baik, sehingga diperoleh nilai $Y=16 / 20 \times 100=80 \%$.

\section{Kesesuaian website Penerimaan Siswa} Baru dengan kebutuhan :

Tabel 10. Pengujian kuesioner soal 8

\begin{tabular}{llllll}
\hline $\begin{array}{l}\text { Pert } \\
\text { any } \\
\text { aan }\end{array}$ & No & Keterangan & $\begin{array}{l}\text { Skal } \\
\text { a } \\
(\mathrm{N})\end{array}$ & $\begin{array}{l}\text { Respond } \\
\text { en }(\mathrm{R})\end{array}$ & $\begin{array}{l}\mathrm{N} . \\
\mathrm{R}\end{array}$ \\
\hline 8 & 1 & Tidak Baik & 1 & 0 & 0 \\
\hline & 2 & Kurang Baik & 2 & 0 & 0 \\
\hline 3 & Baik & 3 & 5 & 15 \\
\hline & Sangat Baik & 4 & 0 & 0 \\
\hline & Jumlah & & 5 & 15 \\
\hline
\end{tabular}

Sumber : Hasil penelitian (2020)

Hasil pengujian beta dengan soal Kesesuaian website Penerimaan Siswa Baru dengan kebutuhan menunjukan bahwa 5 dari 5 responden memberi nilai Baik, sehingga diperoleh nilai $Y=15 / 20 \times 100=$ $75 \%$.

9. Kemudahan dalam melakukan pendaftaran Siswa Baru :

Tabel 11. Pengujian kuesioner soal 9

\begin{tabular}{llllll}
\hline $\begin{array}{l}\text { Pert } \\
\text { any } \\
\text { aan }\end{array}$ & No & Keterangan & $\begin{array}{l}\text { Skal } \\
\text { a } \\
(\mathrm{N})\end{array}$ & $\begin{array}{l}\text { Respond } \\
\text { en }(\mathrm{R})\end{array}$ & $\begin{array}{l}\mathrm{N} . \\
\mathrm{R}\end{array}$ \\
\hline 9 & 1 & Tidak Baik & 1 & 0 & 0 \\
\hline & 2 & Kurang Baik & 2 & 0 & 0 \\
\hline 3 & Baik & 3 & 5 & 15 \\
\hline 4 & Sangat Baik & 4 & 0 & 0 \\
\hline & Jumlah & & 5 & 15 \\
\hline
\end{tabular}

Sumber : Hasil penelitian (2020) 
Hasil pengujian beta dengan soal Kemudahan dalam melakukan pendaftaran Siswa Baru menunjukan bahwa 5 dari 5 responden memberi nilai Baik, sehingga diperoleh nilai $Y=15 / 20 \times 100=75 \%$.

10. Kenyamanan dalam menggunakan website Penerimaan Siswa Baru secara keseluruhan :

Tabel 12. Pengujian kuesioner soal 10

\begin{tabular}{|c|c|c|c|c|c|}
\hline $\begin{array}{l}\text { Pert } \\
\text { any } \\
\text { aan }\end{array}$ & No & Keterangan & $\begin{array}{l}\text { Ska } \\
\text { a } \\
\text { (N) }\end{array}$ & $\begin{array}{l}\text { Respond } \\
\text { en }(\mathrm{R})\end{array}$ & $\begin{array}{l}\mathrm{N} . \\
\mathrm{R}\end{array}$ \\
\hline \multirow[t]{5}{*}{10} & 1 & Tidak Baik & 1 & 0 & 0 \\
\hline & 2 & Kurang Baik & 2 & 0 & 0 \\
\hline & 3 & Baik & 3 & 2 & 6 \\
\hline & 4 & Sangat Baik & 4 & 3 & 12 \\
\hline & & Jumlah & & 5 & 18 \\
\hline
\end{tabular}

Sumber : Hasil penelitian (2020)

Hasil pengujian beta dengan soal Kenyamanan dalam menggunakan website Penerimaan Siswa Baru menunjukan bahwa 2 dari 5 responden memberi nilai Baik, 3 dari 5 memberikan nilai sangat baik, sehingga diperoleh nilai $Y=18 / 20 \times 100=90 \%$.

\section{Kesimpulan}

Hasil kesimpulan dari pengembangan penelitian terdahulu yaitu, dengan pengujian alpha menghasilkan informasi bahwa aplikasi yang telah dirancang memiliki nilai valid atau sesuai dengan harapan yang diinginkan dan pengujian beta menghasilkailialai rata-rata sebagai berikut untuk soal no 1 dengan nilai $75 \%$, soal no 2 dengan nilai $85 \%$, soal no 3 dengan nilai $80 \%$, soal no 4 dengan nilai $75 \%$, soal no 5 dengan nilai $75 \%$, soal no 6 dengan nilai $75 \%$, soal no 7 dengan nilai $80 \%$, soal no 8 dengan nilai $75 \%$, soal no 9 dengan nilai $75 \%$, soal no 10 dengan nilai $90 \%$. Dengan rata-rata nilai $78,5 \%$.

\section{Referensi}

At Taufiq, M. H., \& Hidayati, A. (2016). Rancang Bangun Aplikasi Biro Travel dengan SMS Gateway dan Google Maps API. Multinetics, 2(1), 43. https://doi.org/10.32722/vol2.no1.2016 .pp43-48

Cahyani, N. M., Indriyanto, E., \& Masripah, S. (2016). Uji Validitas dan Reabilitas Terhadap Implementasi Aplikasi Penjualan dan Pembelian. Infrmation
System For Educators and Profesionals, 1(1), 21-34.

Galin, D. (2018). Software Quality Concepts and Practile (1st ed). New Jersey: Wiley.

Masripah, S., \& Ramayanti, L. (2019). Pengujian Black box Pada Sistem Informasi Penerimaan Siswa Baru Berbasis Web. 4(1), 1-12.

Safitri, N., \& Pramudita, R. (2018). Pengujian Black box Menggunakan Metode Cause Effect Relationship Testing. Information Management For Educators And Professionals, 3(1), 101-110.

Suandi, A., Khasanah, F. N., \& Retnoningsih, E. (2017). Pengujian Sistem Informasi E-commerce Usaha Gudang Cokelat Menggunakan Uji Alpha dan Beta. Jurnal INFORM, 2(21), 61-70. Retrieved from https://media.neliti.com/media/publicat ions/234474-pengujian-sisteminformasi-e-commerce-us2bea597f.pdf

Sukamto, R. A., \& Shalahuddin, M. (2014). Rekayasa Perangkat LUnak Struktur dan Berorientasi Objek (Juli 2014). Bandung: Informatika Bandung.

Tutorialspoint. (n.d.). Retrieved from https://www.tutorialspoint.com/softwar e_testing_dictionary/beta_testing.htm 